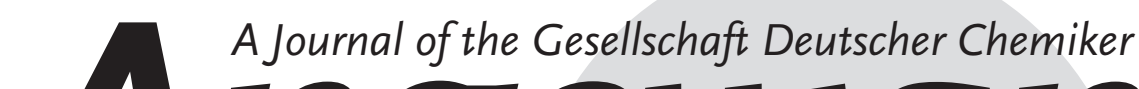 \\ Accepted Article
}

Title: Unraveling the Electrical and Magnetic Properties of Layered Conductive Metal-Organic Framework With Atomic Precision

Authors: Zheng Meng, Christopher G. Jones, Sidra Farid, Islam Ullan Khan, Hosea M. Nelson, and Katherine A. Mirica

This manuscript has been accepted after peer review and appears as an Accepted Article online prior to editing, proofing, and formal publication of the final Version of Record (VoR). This work is currently citable by using the Digital Object Identifier (DOI) given below. The VoR will be published online in Early View as soon as possible and may be different to this Accepted Article as a result of editing. Readers should obtain the VoR from the journal website shown below when it is published to ensure accuracy of information. The authors are responsible for the content of this Accepted Article.

To be cited as: Angew. Chem. Int. Ed. 10.1002/anie.202113569

Link to VoR: https://doi.org/10.1002/anie.202113569 


\title{
Unraveling the Electrical and Magnetic Properties of Layered Conductive Metal-Organic Framework With Atomic Precision
}

\author{
Zheng Meng, ${ }^{[a]}$ Christopher G. Jones, ${ }^{[b]}$ Sidra Farid, ${ }^{[c]}$ Islam Ullah Khan, ${ }^{[c, d]}$ Hosea M. Nelson, ${ }^{[b]}$ \\ Katherine A. Mirica*[a]
}

[a] Dr. Z. Meng, Prof. Dr. K. A. Mirica

Department of Chemistry

Dartmouth College

Burke Laboratory, Hanover, NH 03755, United States

E-mail: katherine.a.mirica@dartmouth.edu

[a] C. G. Jones, Prof. Dr. H. M. Nelson

The Arnold and Mabel Beckman Laboratory of Chemical Synthesis,

Division of Chemistry and Chemical Engineering,

California Institute of Technology,

Pasadena, California 91125, United States

E-mail: hosea@caltech.edu

[c] S. Farid, Prof. Dr. I. U. Khan

Material Chemistry Laboratory, Department of Chemistry

GC University

Lahore 54000, Pakistan

[d] Prof. Dr. I. U. Khan

Department of Chemistry

University of Mianwali

Mianwali 42200, Pakistan.

Supporting information for this article is given via a link at the end of the document.

\begin{abstract}
This paper describes structural elucidation of a layered conductive metal-organic framework (MOF) material $\mathrm{Cu}_{3}\left(\mathrm{C}_{6} \mathrm{O}_{6}\right)_{2}$ by microcrystal electron diffraction with sub-angstrom precision. This insight enables the first identification of an unusual $\pi$-stacking interaction in a layered MOF material characterized by an extremely short $(2.70 \AA)$ close packing of the ligand arising from pancake bonding. Band structure analysis suggests semiconductive properties of the MOF, which are likely related to the localized nature of pancake bonds and the formation of a singlet dimer of the ligand. The spin of $\mathrm{Cu}(\mathrm{II})$ within the Kagomé arrangement dominates the paramagnetism of the MOF, leading to strong geometrical magnetic frustration.
\end{abstract}

\section{Introduction}

The emergence of layered two-dimensional (2D) electrically conductive MOFs ${ }^{[1]}$ as a new generation of $2 \mathrm{D}$ materials, ${ }^{[2]}$ has offered opportunities for innovation in electronics, ${ }^{[3]}$ magnetics, ${ }^{[4]}$ chemiresistive sensing, ${ }^{[5]}$ electrocatalysis, ${ }^{[6]}$ and energy storage. ${ }^{[7]}$ In 2D layered conductive MOFs, the connection of ligands and metal nodes determines the topology and environment of the nanochannel, and governs the electronic coupling between the subunits that dictate the emergent electrical ${ }^{[1]}$ and magnetic properties of the overall material. ${ }^{[8]}$ This electronic coupling can be extremely sensitive to the exact atomic arrangement of molecular components and the stacking of layers within the MOF crystal. ${ }^{[9]}$ Due to electronic coupling between adjacent layers, stacking features exert dramatic influence upon the electronic properties in other 2D layered materials. ${ }^{[10]}$ Achieving a similar level of control in MOFs requires clear structural elucidation of the molecular details and stacking features of this class of materials with atomic precision. ${ }^{[9]}$
The self-assembly of $2 \mathrm{D}$ conductive MOFs involves multiple and interrelated processes, including deprotonation, redox reactions, and coordination polymerization. The complexity of controlling the thermodynamics and kinetics of these processes has posed considerable challenges for obtaining crystals amendable for single crystal X-ray diffraction (SXRD) analysis. To date, access to single crystal structures of 2D conductive MOFs remains highly limited. ${ }^{[11]}$ With few exceptions, ${ }^{[11]} 2 D$ conductive MOFs thus far have been obtained as polycrystalline powders with moderate crystallinity, small crystallite size, disordered interlayer stacking, and/or unidentified pore environment. ${ }^{[1]}$ The lack of knowledge of single crystal structures with atomic precision has significantly hampered the understanding of structure-property relationships. $\left.{ }^{[16,9 a}, 11 \mathrm{c}\right]$ Although combining powder X-ray diffraction ( $P X R D)$ with quantum calculations has yielded structural insight into selected 2D conductive MOFs, ${ }^{[9 a}$, 12] this approach offers limited information about atomic positions, geometric parameters, stacking modes, and arrangement of guest molecules within pores. While additional insight into these parameters can emerge from sophisticated electron microscopy techniques, ${ }^{\text {[11a, }}$ 11b] developing and implementing additional methods that can offer direct structural insight into 2D layered MOFs with atomic precision are highly demanded.

Recently, the emerging technique of microcrystalline electron diffraction (MicroED) ${ }^{[13]}$ has been employed to characterize a range of compounds including large biological macromolecules, ${ }^{[14]}$ small molecules, ${ }^{[15]}$ and organometallic complexes. ${ }^{[16]}$ Unlike X-rays, electrons possess both charge and mass, allowing them to interact more strongly with matter, thus yielding high-quality diffraction data on sub-micron crystals several orders of magnitude smaller than those required for 
SXRD analysis. Thus, MicroED is particularly advantageous for the structural determination of conductive MOFs whose synthetic routes are difficult to adapt to growing sufficiently large single crystals for conventional X-ray analysis. Indeed, several studies have shown the use of electron diffraction for the unambiguous structural characterization of several classes of materials, ${ }^{[17]}$ such as zeolites, ${ }^{[18]}$ MOFs, ${ }^{[11 c,}$ 19] and covalent organic frameworks. ${ }^{[20]}$ Despite these successful implementations, the application of MicroED for structural determination of $2 \mathrm{D}$ conductive MOFs remains extremely limited. ${ }^{[11 c]}$
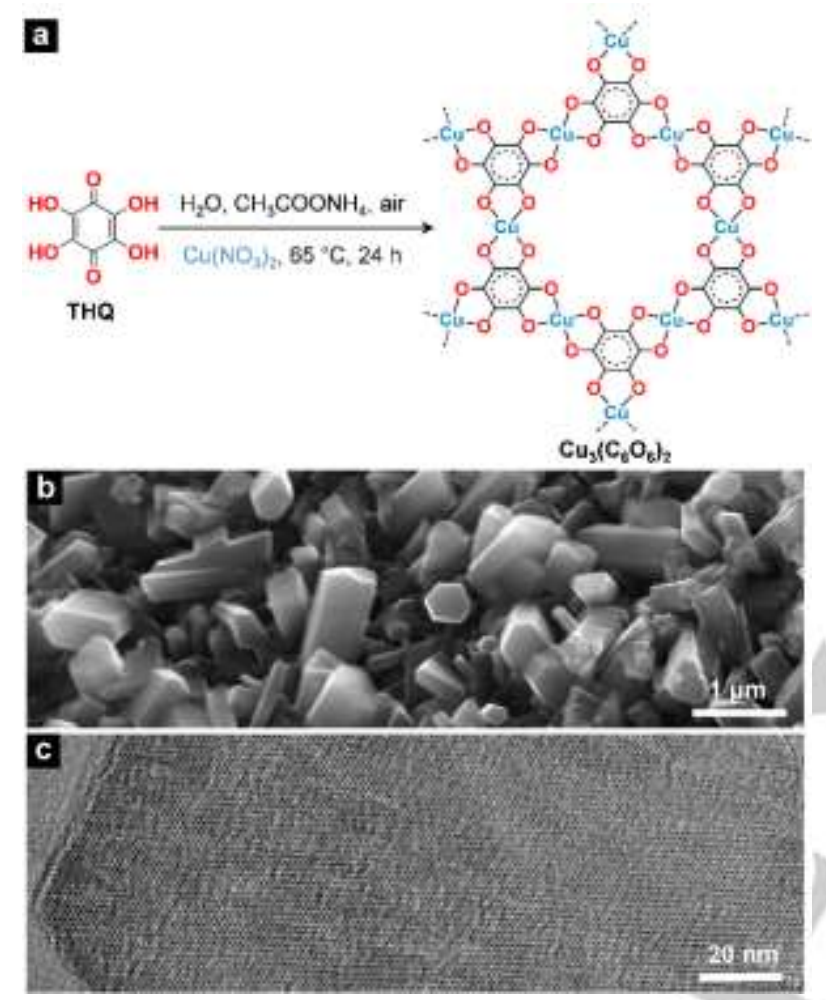

Figure 1. The synthetic scheme, chemical structure, and electron microscopy images of $\mathrm{Cu}_{3}\left(\mathrm{C}_{6} \mathrm{O}_{6}\right)_{2}$ MOF. (a) The synthetic scheme for the formation of $\mathrm{Cu}_{3}\left(\mathrm{C}_{6} \mathrm{O}_{6}\right)_{2}$. (b) SEM and (c) TEM characterization of $\mathrm{Cu}_{3}\left(\mathrm{C}_{6} \mathrm{O}_{6}\right)_{2}$.

This paper describes an unambiguous elucidation of the structure of $\mathrm{Cu}_{3}\left(\mathrm{C}_{6} \mathrm{O}_{6}\right)_{2}$ by MicroED with sub-angstrom precision $(0.8 \AA)$ to provide information on features of interlayer packing, variations of the coordination, and the presence of water guests. We demonstrate that the ligand embedded in the two fully eclipsed layers of the MOF is cofacially stacked with a remarkably short interplanar distance of $2.70 \AA$. This extremely short $\pi$-stacking distance suggests the formation of the pancake bonds between the ligands, which represents the first discovery of this type of interaction in $2 \mathrm{D}$ layered materials. $\mathrm{Cu}_{3}\left(\mathrm{C}_{6} \mathrm{O}_{6}\right)_{2}$ exhibits a bulk electrical conductivity of $1.2 \times 10^{-6} \mathrm{~S} \mathrm{~cm}^{-1}$ at room temperature with an activation energy of $0.47 \mathrm{eV}$. Band structure analysis supports that the semiconductive feature of $\mathrm{Cu}_{3}\left(\mathrm{C}_{6} \mathrm{O}_{6}\right)_{2}$ may be related to the localized nature of the pancake bonds. As pancake bonding leads to the formation of singlet dimers of the ligand between adjacent layers of the MOF, this structural feature leaves the spins of $\mathrm{Cu}$ (II) as the dominant contributor to the paramagnetism of $\mathrm{Cu}_{3}\left(\mathrm{C}_{6} \mathrm{O}_{6}\right)_{2}$. The $\mathrm{Cu}(\mathrm{II})$ ions in a $2 \mathrm{D}$ Kagomé network of the $\mathrm{Cu}_{3}\left(\mathrm{C}_{6} \mathrm{O}_{6}\right)_{2}$ MOF experience strong geometric magnetic frustration. Our study provides fundamental insights into how the unique stacking features can affect the electrical and magnetic properties of $2 \mathrm{D}$ layered conductive MOFs.

\section{Results and Discussion}

Synthesis and Structural Elucidation. In our optimized conditions, $\mathrm{Cu}_{3}\left(\mathrm{C}_{6} \mathrm{O}_{6}\right)_{2}$ was synthesized by adding tetrahydroxy1,4-benzoquinone (THQ) solid to a copper nitrate or acetate solution in water in the presence of ammonium acetate under a gentle air bubbling at $65^{\circ} \mathrm{C}$ for $24 \mathrm{~h}$ (Figure 1a, see section 2 in Supporting Information for details). $\mathrm{Cu}_{3}\left(\mathrm{C}_{6} \mathrm{O}_{6}\right)_{2}$ was obtained as a microcrystalline powder comprising crystals with hexagonshaped rods at the submicrometer to micrometer scale and hexagonal pores, as observed by scanning electron microscopy (SEM, Figure 1b) and transmission electron microscopy (TEM, Figure 1c), respectively. Compared with the previous report, ${ }^{[21]}$ our synthetic conditions significantly increased the crystallinity (Figures S1-S2) and crystallite size (nanometer vs micrometer, Figure S3) of $\mathrm{Cu}_{3}\left(\mathrm{C}_{6} \mathrm{O}_{6}\right)_{2}$ material. This improvement of the crystallite size to micrometer dimensions was a key advance that ultimately enabled the first structure elucidation of $\mathrm{Cu}_{3}\left(\mathrm{C}_{6} \mathrm{O}_{6}\right)_{2}$ MOF using MicroED with atomic-level precision.

The crystal of $\mathrm{Cu}_{3}\left(\mathrm{C}_{6} \mathrm{O}_{6}\right)_{2}$ was illuminated by a low dose electron beam $\left(<0.03 e^{-} / \AA^{2} s\right)$, while being continuously rotated. The diffraction data were processed and refined using broadly available software for X-ray crystallography (see section 9 in Supporting Information). The structure of $\mathrm{Cu}_{3}\left(\mathrm{C}_{6} \mathrm{O}_{6}\right)_{2}$ was resolved with a high resolution of up to $0.80 \AA \AA^{[22]}$ This resolution is on par with the best resolution achieved by electron diffraction for MOF PCN-415 $(0.75 \AA)^{[19 b]}$ and comparable to that of the SXRD structure of COF-300 (0.85 $\AA) .{ }^{[23]} \mathrm{Cu}_{3}\left(\mathrm{C}_{6} \mathrm{O}_{6}\right)_{2}$ has a honeycomb-type network formed by the coordination between the $\mathrm{Cu}$ ion and $\mathrm{C}_{6} \mathrm{O}_{6}$ unit in a ratio of 2:3 (Figure 2a). Cu ions link the ligand through the chelation sites from the direction of the $C_{2}$ symmetry axis of the ligand. We identified two types of $\mathrm{Cu}$ ions, $\mathrm{Cu}^{\alpha}$ and $\mathrm{Cu}^{\beta}$ in a molar ratio of $1: 2$, which have slightly different distortions in their square planar coordination geometry (Figure 2c). $\mathrm{Cu}^{\alpha}$ adopts a nearly perfect square planar coordination geometry in $\mathrm{Cu}^{\alpha} \mathrm{O}_{4}$ units with a dihedral angle of only $\sim 2.2^{\circ}$ between the two planes established by $\mathrm{O}-\mathrm{Cu}^{\alpha}-\mathrm{O}$ atoms. The corresponding dihedral angle in $\mathrm{Cu}^{\beta} \mathrm{O}_{4}$ units is $\sim 7.4^{\circ}$. These imperfect square planar connections lead the layers of the MOF to be slightly bent. These layers exhibit a unique double-layer and mixed stacking of $A A A^{\prime} A^{\prime}$ with an alternating fully eclipsed $\left(A A\right.$ and $\left.A^{\prime} A^{\prime}\right)$ and a slipped-parallel packing $\left(A A^{\prime}\right.$ and $A A^{\prime}$, relative in-plane displacement of $1.9 \AA$ ) between two adjacent layers (Figure $2 b$ ). This observation is in stark contrast to other layered conductive MOFs that show either fully eclipsed,

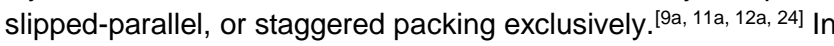
$\mathrm{Cu}_{3}\left(\mathrm{C}_{6} \mathrm{O}_{6}\right)_{2}$, the average layer-to-layer distance (see Figure $\mathrm{S} 14$ for definition) for the fully eclipsed and slipped-parallel packings with honeycomb pores of $2.9 \AA$ and $3.1 \AA$, respectively. The value of $2.9 \AA$ is much shorter than those observed in MOFs with honeycomb lattices based on hexaiminobenzene $(\sim 3.2-3.3 \AA)^{[7 b}$, ${ }^{24]}$ and hexasubstitubed triphenylene $\left(\sim 3.3 \AA\right.$ ). ${ }^{[11 a, ~ 12 a, ~ 25] ~}$ 

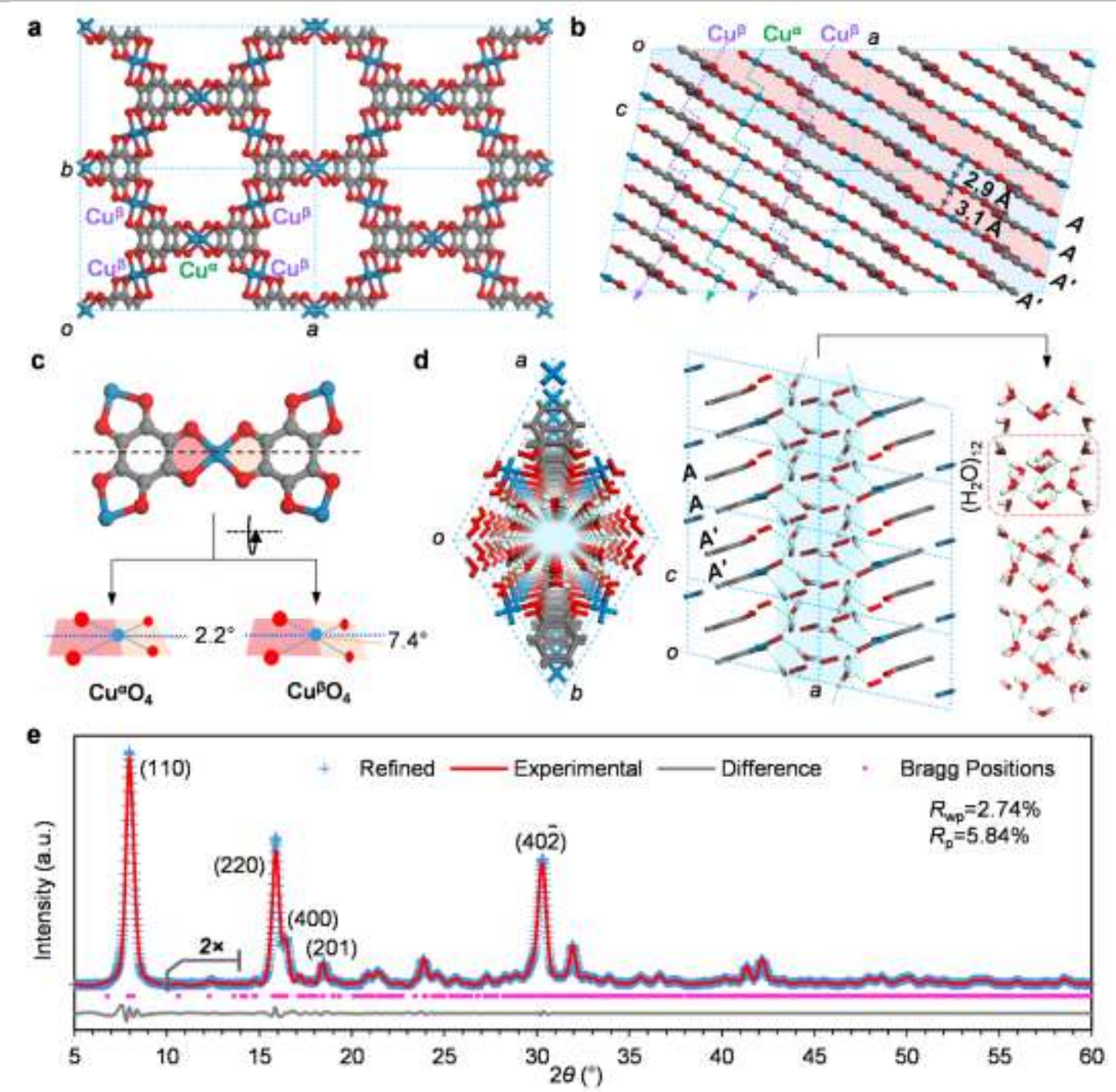

Figure 2. Single crystal structure of $\mathrm{Cu}_{3}\left(\mathrm{C}_{6} \mathrm{O}_{6}\right)_{2}$ resolved by MicroED and pXRD analysis of the bulk powder of $\mathrm{Cu}_{3}\left(\mathrm{C}_{6} \mathrm{O}_{6}\right)_{2}$. $(\mathrm{a}) \mathrm{Front}$ view of the crystal structure Two types of structurally different $\mathrm{Cu}$ in $\mathrm{Cu}_{3}\left(\mathrm{C}_{6} \mathrm{O}_{6}\right)_{2}$ were labeled by $\mathrm{Cu}^{\alpha}$ and $\mathrm{Cu}^{\beta}$, respectively. (b) Side view of the structure showing a double-layered and mixed type of fully eclipsed and slipped parallel stacking. The purple and green arrows depict the alignment of $\mathrm{Cu}^{\alpha}$ and $\mathrm{Cu}^{\beta}$, respectively, along the directions of the

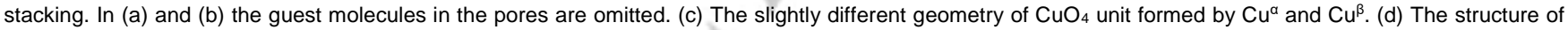
the water cluster $\left[\left(\mathrm{H}_{2} \mathrm{O}\right)_{12}\right]_{n}$ formed inside the channel of $\mathrm{Cu}_{3}\left(\mathrm{C}_{6} \mathrm{O}_{6}\right)_{2}$. The structure was shown as the equivalent primitive cell to highlight a single-channel structure. (e) Overlay of the experimental and Pawley refinement pXRD traces for $\mathrm{Cu}_{3}\left(\mathrm{C}_{6} \mathrm{O}_{6}\right)_{2}$ with key diffraction planes labeled.

$\mathrm{Cu}_{3}\left(\mathrm{C}_{6} \mathrm{O}_{6}\right)_{2}$ showed solvent-accessible nanopores with a diameter of $\sim 1.1 \mathrm{~nm}$ containing confined water clusters. Regeneration of the positions of hydrogen atoms of water molecules by DFT calculations suggested a hydrogen-bonded water assembly of dodecamer $\left(\mathrm{H}_{2} \mathrm{O}\right)_{12}$ formed within the two adjacent fully eclipsed layers. This assembly appeared aligned along the channel to form a longitudinally extended cluster $\left[\left(\mathrm{H}_{2} \mathrm{O}\right)_{12}\right]_{n}$ (Figure 2d). The above analysis suggested a chemical formula of $\mathrm{Cu}_{3}\left(\mathrm{C}_{6} \mathrm{O}_{6}\right)_{2} \cdot 6 \mathrm{H}_{2} \mathrm{O}$, which is in excellent agreement with elemental analysis (Table S2) and thermogravimetric analysis (Figure S24). Pawley refinement of the structure resolved by MicroED analysis against experimental pXRD $(\lambda=1.5406 \AA)$ yielded an excellent match (Figure $2 \mathrm{e}$ and section 10 in Supporting Information). These results demonstrated good consistency with the structure resolved by MicroED and experimental $\mathrm{pXRD}$, as well as excellent crystallinity and purity of the bulk material of $\mathrm{Cu}_{3}\left(\mathrm{C}_{6} \mathrm{O}_{6}\right)_{2}$.
Analysis of Oxidation States of Constituents in $\mathrm{Cu}_{3}\left(\mathrm{C}_{6} \mathrm{O}_{6}\right)_{2}$. An accurate determination of the valency of constituents in MOFs is critical for interpreting their electronic properties, including charge transport and spin behavior. X-ray photoelectron spectroscopy (XPS) confirmed the presence of $\mathrm{C}$, $\mathrm{O}$, and $\mathrm{Cu}$ in $\mathrm{Cu}_{3}\left(\mathrm{C}_{6} \mathrm{O}_{6}\right)_{2}$ sample. The deconvolution of highresolution XPS scan of $\mathrm{Cu} 2 \mathrm{p}$ range ${ }^{[26]}$ in $\mathrm{Cu}_{3}\left(\mathrm{C}_{6} \mathrm{O}_{6}\right)_{2}$ suggested a dominant distribution of $\mathrm{Cu}(\mathrm{II})$ over $\mathrm{Cu}(\mathrm{I})$ with a $\mathrm{Cu}(\mathrm{II}): \mathrm{Cu}(\mathrm{I})$ ratio of 95:5 (Figure 3a, see section 7 in Supporting Information). High-resolution XPS analysis of the $C$ 1s revealed a nearly $1: 1$ distribution of $-\mathrm{C}=\mathrm{O}$ and $-\mathrm{C}-\mathrm{O}$ (Figure $3 b$ ), in line with the observation of $\mathrm{C}=\mathrm{O}$ and $\mathrm{C}-\mathrm{O}$ stretching in Fourier-transform infrared spectroscopy and Raman spectroscopy (section 4 in Supporting Information). These results supported the existence of the ligand is in a tris(semiquinone) form on average, equivalent to an anionic radical of $\left[\mathrm{C}_{6} \mathrm{O}_{6}\right]^{3-}$. However, the possibility of an equal distribution of ligand in $-2\left(\left[\mathrm{C}_{6} \mathrm{O}_{6}\right]^{2-}\right)$ and $-4\left(\left[\mathrm{C}_{6} \mathrm{O}_{6}\right]^{4-}\right)$ states as a mixed valency cannot be excluded 
(upper part in Figure 3c). A combination of $\mathrm{Cu}^{2+}$ ions and the ligand with a formal averaged charge of -3 in a ratio of $3: 2$ should give a charge-neutral framework for $\mathrm{Cu}_{3}\left(\mathrm{C}_{6} \mathrm{O}_{6}\right)_{2}$, consistent with the crystal structure resolved by MicroED and elemental analysis (Table S2). The above analysis demonstrated that the charge neutral $\mathrm{Cu}_{3}\left(\mathrm{C}_{6} \mathrm{O}_{6}\right)_{2}$ MOF in this work exhibited a more oxidized state in its skeleton than the negatively charged scaffold of this analog reported previously. ${ }^{[21 a]}$ We attribute the charge neutrality realized in this work to continuous air bubbling during synthesis.

To gain more insights into the oxidation state of the ligand, we turned to bond-length analysis. Previous studies of metalsemiquinone complexes showed that the $\mathrm{C}-\mathrm{O}$ bond length is indicative of the degree of oxidation of the semiquinone fragment. ${ }^{[27]}$ Shorter $\mathrm{C}-\mathrm{O}$ bonds correlate with more oxidized (quinone-type) character, whereas longer $\mathrm{C}-\mathrm{O}$ bonds correspond to reduced (catechol-type) character. Based on the $\mathrm{C}-\mathrm{O}$ and $\mathrm{C}-\mathrm{C}$ bond lengths, the structure of the $\mathrm{Cu}_{3}\left(\mathrm{C}_{6} \mathrm{O}_{6}\right)_{2}$ revealed two kinds of slightly different $\mathrm{C}_{6} \mathrm{O}_{6}$ ligands within the MOF (lower part in Figure $3 \mathrm{c}$ ) with averaged $\mathrm{C}-\mathrm{O}$ bond lengths of $1.28(1) \AA$. This value was close to the average $\mathrm{C}$-O bond lengths in a $\mathrm{Cu}(\mathrm{II})$ bis-semiquinonate complex $(1.288 \AA)^{[27 b]}$ and a Cu(II) triphenylene tris(semiquinone) complex (1.283 $\AA$ ) (see Table S6 and Figure S22 for comprehensive comparison). This consistency suggested that ligands within the MOF were likely in a tris(semiquinone) state (see detailed discussion in section 11 in Supporting Information).

Extremely Close Packing of the Ligand in $\mathrm{Cu}_{3}\left(\mathrm{C}_{6} \mathrm{O}_{6}\right)_{2}$. Our analysis showed that the two types of ligands were alternatively embedded in the two adjacent fully eclipsed layers within the MOF. The ligands were cofacially stacked with an interplanar distance (averaged $\mathrm{C}$ to $\mathrm{C}$ distances in the ligand) of only 2.73 $\AA$ (Figure 3d). This value represents one of the shortest $\pi-\pi$ stacking distances (plane to plane or centroid to plane) ${ }^{[28]}$ that has been experimentally approached and identified in all structures reported to date. ${ }^{[29]}$ Considering that conventional $\pi-$ $\pi$ stacking distances are in the range of $3.0-3.9 \AA_{,},{ }^{[28]}$ this extremely short distance suggested the presence of strong intermolecular interactions, for example, charge transfer interaction ${ }^{[30]}$ or spin-spin coupling interaction, ${ }^{[31]}$ between the two types of $\mathrm{C}_{6} \mathrm{O}_{6}$ ligands.

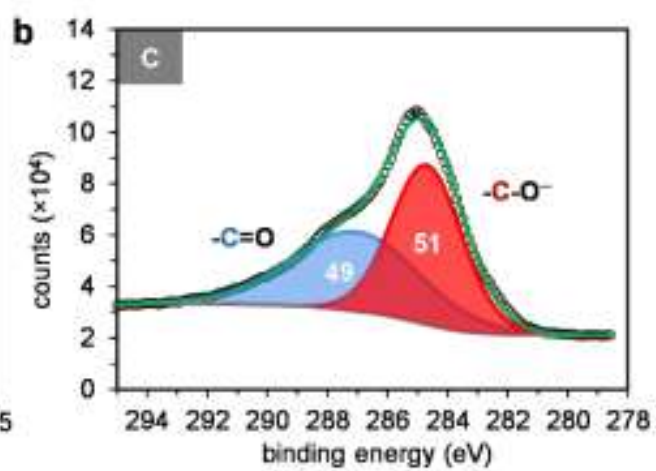

d
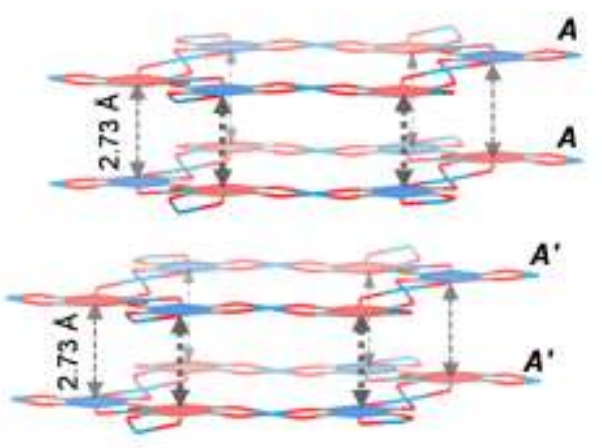

Figure 3. Oxidation state analysis of the metal and ligand in $\mathrm{Cu}_{3}\left(\mathrm{C}_{6} \mathrm{O}_{6}\right)_{2} \mathrm{MOF}$ and extremely close stacking of the ligand. The high-resolution XPS scan of (a) $\mathrm{Cu}$ $2 \mathrm{p}$ and (b) $\mathrm{C} 1 \mathrm{~s}$ range (after $\mathrm{Ar}^{+}$sputter etching) of $\mathrm{Cu}_{3}\left(\mathrm{C}_{6} \mathrm{O}_{6}\right)_{2}$ MOF with area percentages of the deconvoluted peaks given. (c) Representative resonant structures of $\mathrm{C}_{6} \mathrm{O}_{6}$ ligand in $-2,-3$, and -4 charged states (upper part). Two types of $\mathrm{C}_{6} \mathrm{O}_{6}$ ligands (colored in red and blue) as being incorporated in $\mathrm{Cu}_{3}\left(\mathrm{C}_{6} \mathrm{O}_{6}\right)_{2} \mathrm{MOF}$ with slightly different $\mathrm{C}-\mathrm{O}$ bonds (lower part). (d) The arrangement of the two types of $\mathrm{C}_{6} \mathrm{O}_{6}$ ligands in $\mathrm{Cu}_{3}\left(\mathrm{C}_{6} \mathrm{O}_{6}\right)_{2}$.

Spin pairing has been previously observed in $\pi$-assemblies of phenalenyl, ${ }^{[32]}$ viologen cation, ${ }^{[33]}$ naphthalenediimide anion, ${ }^{[34]}$ tetracyanoquinodimethane anion, ${ }^{[35]}$ tetrathiafulvalene cation, ${ }^{[36]}$ and others. ${ }^{[31 a, 37]}$ In these systems, efficient $\pi-\pi$ orbital overlap provides the driving force for the stabilization of a dimer that is responsible for contact distances significantly shorter and interaction energies larger than those of typical van der Waals interactions. This interaction has been described as "pancake bonding". ${ }^{31 a}$, 32, 34-35, 37a, 38] We hypothesized that analogous interactions may be present within adjacent bilayers of
$\mathrm{Cu}_{3}\left(\mathrm{C}_{6} \mathrm{O}_{6}\right)_{2} \mathrm{MOF}$, considering the cofacial alignment and the very short interplanar distance between the ligands with a formal radical state.

Given that the spin state of the ligand can be significantly affected by the radical pairing interaction, electron paramagnetic resonance (EPR) spectroscopy was performed to study the spin characteristics of MOF $\mathrm{Cu}_{3}\left(\mathrm{C}_{6} \mathrm{O}_{6}\right)_{2}$. EPR of $\mathrm{Cu}_{3}\left(\mathrm{C}_{6} \mathrm{O}_{6}\right)_{2}$ at $77 \mathrm{~K}$ (Figure $4 \mathrm{a}$ ) and $298 \mathrm{~K}$ both exhibited a broad absorbance band in the range of $2500-4500 \mathrm{G}$, which was ascribed to a Cu- 
centered radical in Cu catecholate-based materials (Figure S12, see Supporting for discussion). ${ }^{[11 \mathrm{c}, 27 \mathrm{c}, 39]}$ The asymmetric shape of the EPR spectra is consistent with the pseudo-square planar coordination of $\mathrm{Cu}$, in which in-plane $\mathrm{Cu} \cdot \cdots \mathrm{O}$ coordination bonds are much longer than $\mathrm{Cu}$ to $\mathrm{O}$ and $\mathrm{Cu}$ to $\mathrm{Cu}$ distances along the axial direction (Figure S33). ${ }^{[40]}$ DFT calculations revealed that the spin density of $\mathrm{Cu}_{3}\left(\mathrm{C}_{6} \mathrm{O}_{6}\right)_{2}$ was predominately centered on the $d_{x 2-y 2}$ orbital of $\mathrm{Cu}$ ions, with the positive and negative signs of spin density for $\mathrm{Cu}^{\alpha}$ and $\mathrm{Cu}^{\beta}$, respectively (Figure $4 \mathrm{~b}$ and section 15 in Supporting Information). Taken together, EPR results and DFT calculations suggested that the unpaired electrons in $\mathrm{Cu}_{3}\left(\mathrm{C}_{6} \mathrm{O}_{6}\right)_{2}$ MOF were centered $\mathrm{Cu}(\mathrm{II})$ centers. The lack of the spin signal from ligands supported the presence of pancake bonded singlet dimers (Figure 3d). This strong interlayer interaction may be beneficial in promoting ordered packing without stacking faults in $\mathrm{Cu}_{3}\left(\mathrm{C}_{6} \mathrm{O}_{6}\right)_{2}$ (Figure S5).

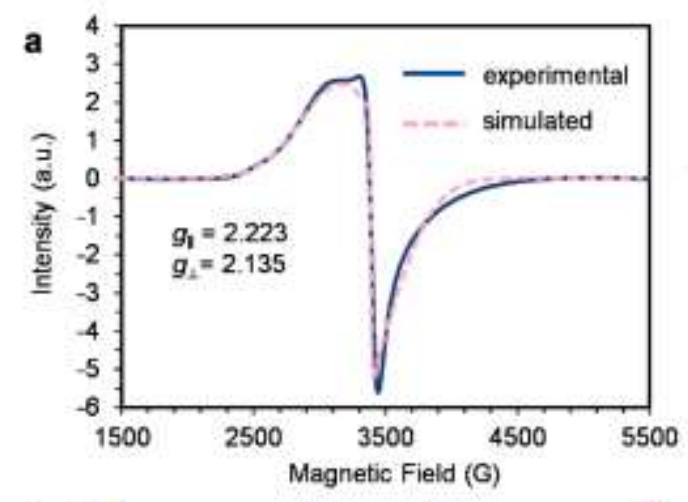

b
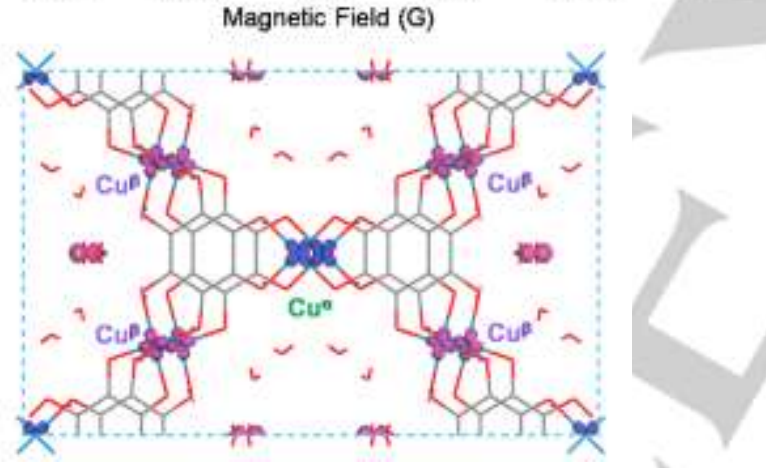

in this study, as well as the charge-neutral skeleton of the structure in this report. Temperature-dependent conductivity tests showed that increasing the temperature to $393 \mathrm{~K}$ increased the conductivity of the material to $1.7 \times 10^{-4} \mathrm{~S} \mathrm{~cm}^{-1}$ (Figure 5a). Fitting of conductivity to temperature revealed Arrhenius-type dependence with an activation energy $\left(E_{\mathrm{a}}\right)$ of $0.47 \mathrm{eV}$ for the charge carrier transport (inset in Figure 5a). UV-vis-NIR spectroscopy showed relatively broad absorption bands that extended to the NIR region (Figure 5b). Plotting the UV-vis-NIR spectra in Tauc coordinates resulted in an optical bandgap ( $E_{O}$, gap) of $0.95 \mathrm{eV}$ for $\mathrm{Cu}_{3}\left(\mathrm{C}_{6} \mathrm{O}_{6}\right)_{2}$ (inset in Figure $5 \mathrm{~b}$ ). These results suggested the semiconductive property of the bulk material of $\mathrm{Cu}_{3}\left(\mathrm{C}_{6} \mathrm{O}_{6}\right)_{2}$.

To further understand the intrinsic electrical properties of $\mathrm{Cu}_{3}\left(\mathrm{C}_{6} \mathrm{O}_{6}\right)_{2}$, we performed the spin-polarized DFT calculations of band structure using meta-generalized gradient approximation functional (section 15 in Supporting Information). The calculated band structure of $\mathrm{Cu}_{3}\left(\mathrm{C}_{6} \mathrm{O}_{6}\right)_{2}$, which included entrapped water molecules, revealed a direct bandgap of $0.14 \mathrm{eV}$ near gamma point, consistent with the semiconducting characteristic of $\mathrm{Cu}_{3}\left(\mathrm{C}_{6} \mathrm{O}_{6}\right)_{2}$ (Figure $5 \mathrm{c}$ ). Although DFT calculations can underestimate the bandgap, ${ }^{[4]]}$ the discrepancy between the theoretical bandgap $(0.14 \mathrm{eV})$ and the relatively large experimental activation energy $(0.47 \mathrm{eV})$ indicated charge hopping barriers between rather localized states. Domain boundaries ${ }^{[16,4 c, 21 a, 24,42]}$, impurities, and defects may also contribute to the magnitude of the activation energy of charge transport in the polycrystalline MOF. The partial density of states (PDOS) showed that the valence band maximum (VBM) comprised exclusive contributions from $p$ orbitals of $\mathrm{O}$ and $\mathrm{C}$ atoms. The conduction band minimum (CBM) exhibited considerable hybridization of $d$ orbitals of $\mathrm{Cu}$ and $p$ orbitals of $\mathrm{O}$ atoms. The calculated minimum carrier effective mass (section 15 in Supporting Information) of VBM along the M-A direction (along reciprocal lattice vector $[0,1, \overline{1}]$ ) was $0.05 \mathrm{me}_{\mathrm{e}}$, much smaller than those for $\mathrm{L}-\mathrm{M}, \mathrm{A}-\Gamma, \Gamma-\mathrm{Z}$, and $\mathrm{Z}-\mathrm{V}$ directions $(0.15$, $2.01,0.18$, and $0.40 m_{e}$, respectively). These differences suggested more efficient transport of charge carriers along the M-A direction than along other directions (Figure 5d).

The calculated orbitals near the VBM were centered on Figure 4. Spin characteristic of MOF $\mathrm{Cu}_{3}\left(\mathrm{C}_{6} \mathrm{O}_{6}\right)_{2}$. (a) EPR spectra of $\mathrm{Cu}_{3}\left(\mathrm{C}_{6} \mathrm{O}_{6}\right)_{2}$ at $77 \mathrm{~K}$. (d) DFT-calculated spin-up (pink) and spin-down (blue) density of $\mathrm{Cu}_{3}\left(\mathrm{C}_{6} \mathrm{O}_{6}\right)_{2}$.

Although pancake bond, as a type of stacking interaction, has been demonstrated in several molecular systems with planar configurations as mentioned earlier, ${ }^{[32-34,38]}$ as far as we know, it has not been previously reported in any $2 \mathrm{D}$ layered materials. The formation of pancake bonds in the $\mathrm{Cu}_{3}\left(\mathrm{C}_{6} \mathrm{O}_{6}\right)_{2}$ suggested a unique type of electronic interlayer coupling between the ligands in the MOF, which can influence the electrical and magnetic properties of this material.

Electrical Properties. With a clear picture of structural features for $\mathrm{Cu}_{3}\left(\mathrm{C}_{6} \mathrm{O}_{6}\right)_{2}$ in mind, we sought to investigate the electrical and magnetic properties of this material. Two-contact probe measurements of the conductivity of $\mathrm{Cu}_{3}\left(\mathrm{C}_{6} \mathrm{O}_{6}\right)_{2}$ gave a bulk conductivity of $1.2 \times 10^{-6} \mathrm{~S} \mathrm{~cm}^{-1}$ at $298 \mathrm{~K}$. This value showed more than one order of magnitude improvement compared with the MOF made from $\mathrm{Cu}(\mathrm{II})$ and THQ in previous reports. ${ }^{[21 a, 21 b]}$ We attributed this increase to the improved crystallinity achieved $\left[\mathrm{C}_{6} \mathrm{O}_{6}\right]^{3-\cdot}$ ligand (Figure $5 \mathrm{e}$, see also Figure S28a) in comparison to the orbitals near the CBM that were mostly centered on $\mathrm{CuO}_{4}$ units (Figure 5f, see also Figure S28b). The composition of these orbitals was consistent with the PDOS analysis. Importantly, we observed that in the calculated orbitals near the VBM, the $p$ orbitals of $C$ exhibited high degree of overlap and formed multicentered bonding orbitals. This observation further corroborated the formation of the pancake bonding of ligand in $\mathrm{Cu}_{3}\left(\mathrm{C}_{6} \mathrm{O}_{6}\right)_{2}$. Because of the unique double-layer and mixed stacking mode of $\mathrm{Cu}_{3}\left(\mathrm{C}_{6} \mathrm{O}_{6}\right)_{2}$, the pancake bonds were found sandwiched between the fully eclipsed layers ( $A A$ or $\left.A^{\prime} A\right)$, while absent between the slipped-parallel layers $\left(A^{\prime} A\right.$ or $\left.A A^{\prime}\right)$. This spatial distribution of the pancake bonds suggested the presence of a localized feature of $\pi$ electrons in the VBM. We hypothesize that this feature likely limits the long-range out-ofplane electron transport in $\mathrm{Cu}_{3}\left(\mathrm{C}_{6} \mathrm{O}_{6}\right)_{2}$ and serves as an important intrinsic reason for the observed moderate conductivity and relatively large activation energy in addition to the contributing factors of domain boundaries. 


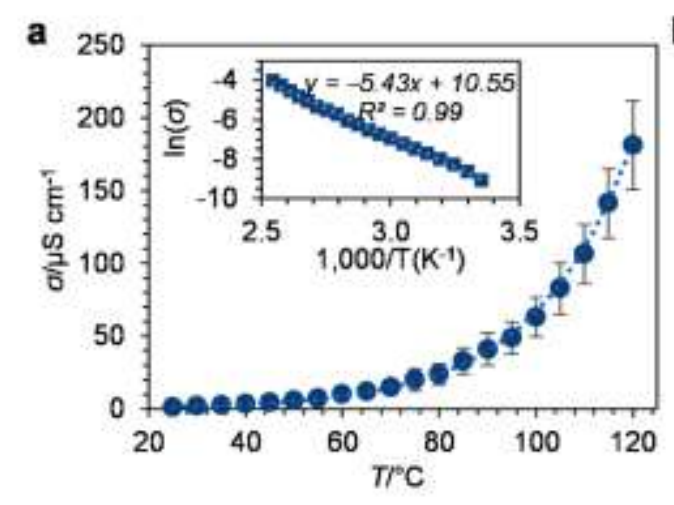

C
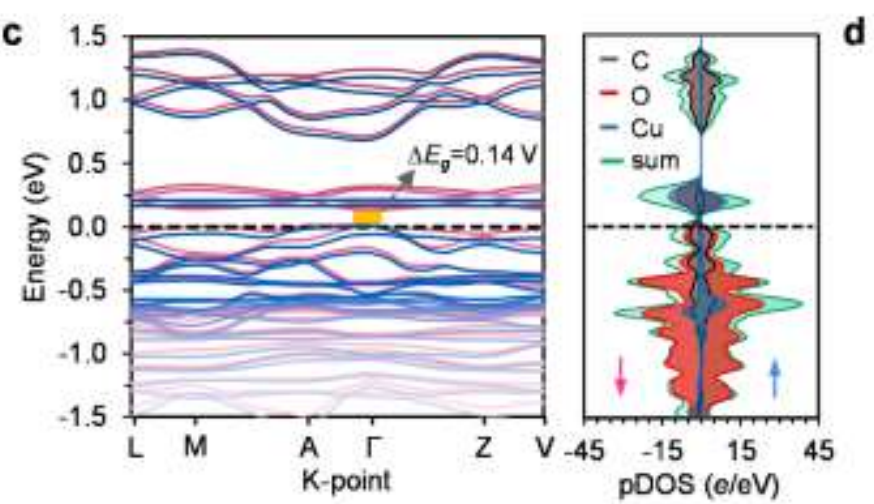

d
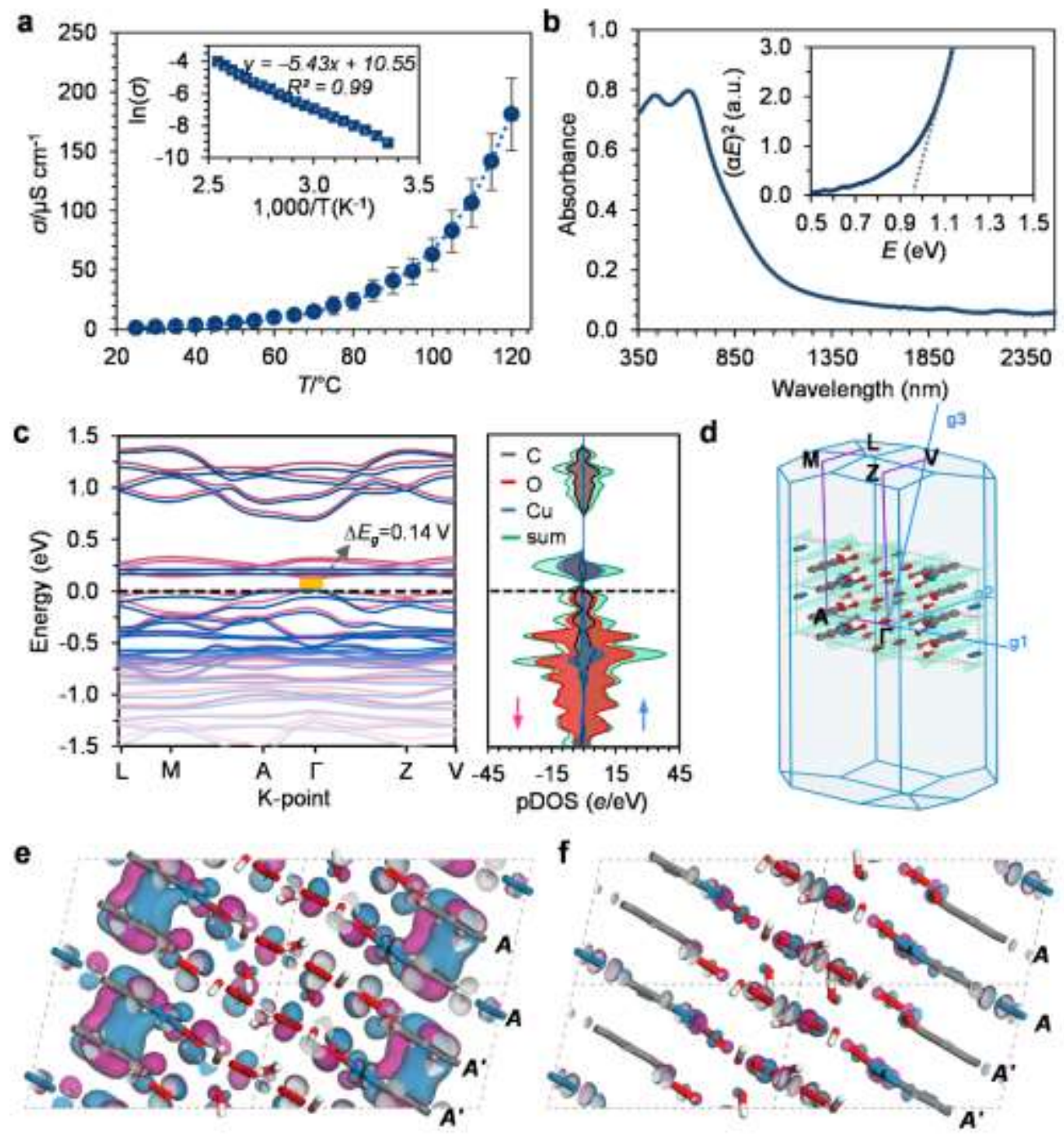

Figure 5. Electrical properties of $\mathrm{Cu}_{3}\left(\mathrm{C}_{6} \mathrm{O}_{6}\right)_{2} \mathrm{MOF}$. (a) Electrical conductivity of $\mathrm{Cu}_{3}\left(\mathrm{C}_{6} \mathrm{O}_{6}\right)_{2}$ pellets as a function of temperature. The inset is the Arrhenius fitting of conductivity to temperature. (b) UV-vis-NIR spectrum of $\mathrm{Cu}_{3}\left(\mathrm{C}_{6} \mathrm{O}_{6}\right)_{2}$ thin film deposited on quartz substrates. The inset is the Tauc plot of the UV-vis absorbance spectra for the estimation of the optical bandgap. (c) Calculated band structure (blue and red lines for spin-up and spin-down electron associated bands, respectively) and projected PDOS for $\mathrm{Cu}_{3}\left(\mathrm{C}_{6} \mathrm{O}_{6}\right)_{2}$ using the structure determined by MicroED with $\mathrm{H}$ atoms of water molecules regenerated. (d) The first Brillouin zone and $\mathrm{K}$ points of $\mathrm{Cu}_{3}\left(\mathrm{C}_{6} \mathrm{O}_{6}\right)_{2}$ MOF. Green planes parallel to $2 \mathrm{D}$ layers are added to guide eyes. Calculated orbitals near the (e) VBM and (f) $\mathrm{CBM}$.

Magnetic Properties. To probe the magnetic properties of $\mathrm{Cu}_{3}\left(\mathrm{C}_{6} \mathrm{O}_{6}\right)_{2} \mathrm{MOF}$, temperature-variable magnetic susceptibility measurements were performed between 1.8-300 K (Figure 6a). The field cooled (FC) and zero field cooled (ZFC) magnetization curves were almost the same in the tested temperature range, indicating a lack of long-range magnetic order down to $1.8 \mathrm{~K}$ and a typical paramagnetic behavior at $1.8-300 \mathrm{~K}$. The magnetic hysteresis tests of $\mathrm{Cu}_{3}\left(\mathrm{C}_{6} \mathrm{O}_{6}\right)_{2}$ MOF at $2 \mathrm{~K}$ and $5 \mathrm{~K}$ did not display any hysteretic behavior (Figure $6 \mathrm{~b}$ and Figure S32), demonstrating the lack of remanent magnetization due to the absence of ferromagnetic ordering. The fitting of paramagnetic susceptibility $X_{\mathrm{m}, \mathrm{p}}$ (see section 16 in Supporting Information) and temperature at $25-300 \mathrm{~K}$ according to Curie-Weiss law provided a nearly linear relationship (inset Figure 6a). This fitting yielded a Curie constant of $1.23 \mathrm{emu} \cdot \mathrm{K} \cdot \mathrm{mol}^{-1}$ (per mole $\left.\mathrm{Cu}_{3}\left(\mathrm{C}_{6} \mathrm{O}_{6}\right)_{2} \cdot 6 \mathrm{H}_{2} \mathrm{O}\right)$ and a Weiss constant $(\theta)$ of $-26.1 \mathrm{~K}$. The Curie constant of $1.20 \mathrm{emu} \cdot \mathrm{K} \cdot \mathrm{mol}^{-1}$ was only slightly higher than the theoretical value expected for three independent spins of $\mathrm{Cu}^{2+}$ with $S=1 / 2\left(1.125 \mathrm{emu} \mathrm{K} \mathrm{mol}^{-1}\right)$. However, this value was much smaller than that for five independent $S=1 / 2$ spins $(1.875$ emu $\mathrm{K} \mathrm{mol}^{-1}$, three $\mathrm{Cu}^{2+}$ and two ligands). Consistently, the effective moment $\left(\mu_{\text {eff }}\right)$ calculated for each $\mathrm{Cu}$ ion in the formula $\mathrm{Cu}_{3}\left(\mathrm{C}_{6} \mathrm{O}_{6}\right)_{2} \cdot 6 \mathrm{H}_{2} \mathrm{O}, 1.788 \mu_{\mathrm{B}}$, was reasonably close to that expected for $\mathrm{Cu}^{2+}$ ion with $\mathrm{S}=1 / 2$ state, $1.73 \mu_{\mathrm{B}}$. These results supported that the paramagnetism of the $\mathrm{Cu}_{3}\left(\mathrm{C}_{6} \mathrm{O}_{6}\right)_{2} \mathrm{MOF}$ at the tested temperature range was mostly from the spin of $\mathrm{Cu}$ centers. The negative Weiss temperature suggested an antiferromagnetic interaction between localized $\mathrm{Cu}^{2+}$ ions moments. ${ }^{[42-43]}$ Further considering the Kagomé arrangement of $\mathrm{Cu}(\mathrm{II})$ ions in $\mathrm{Cu}_{3}\left(\mathrm{C}_{6} \mathrm{O}_{6}\right)_{2}$, the antiferromagnetic interactions between adjacent $\mathrm{Cu}(\mathrm{II})$ spins within the layer (single arrows in Figure 6d) can lead to geometrical frustration. ${ }^{[44]}$ Estimation of the frustration parameter $f$, defined as $|\theta| / T_{c},{ }^{[45]}$ gave $f>14$, which supported a strong suppression of magnetic ordering that may result from geometrical frustration. 

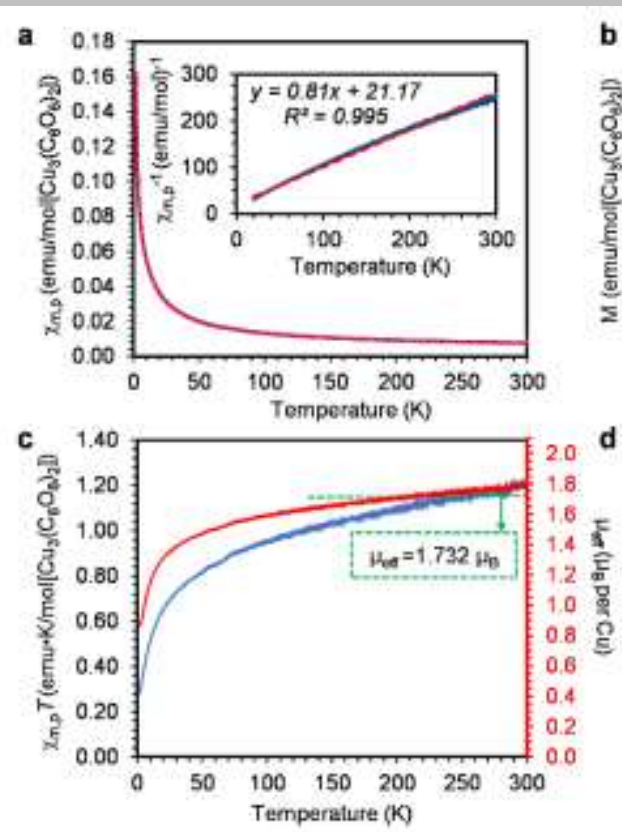
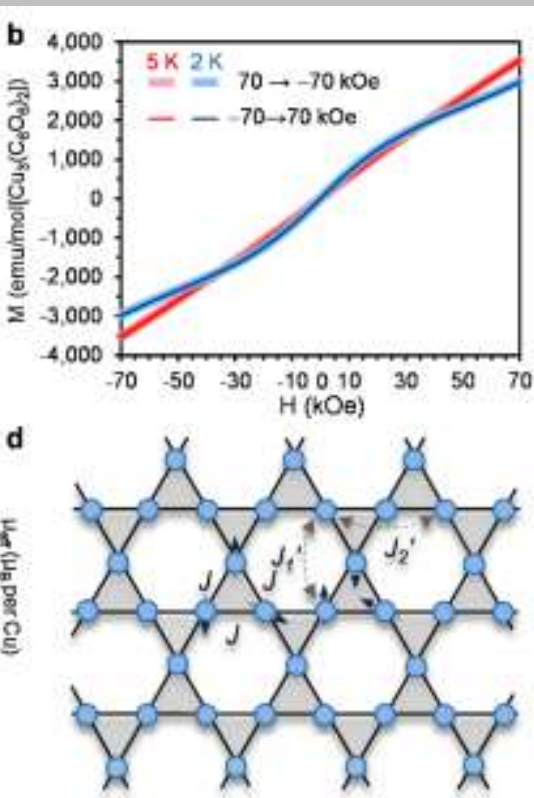

Figure 6. Magnetic properties of $\mathrm{Cu}_{3}\left(\mathrm{C}_{6} \mathrm{O}_{6}\right)_{2} \mathrm{MOF}$. (a) ZFC (solid blue line) and $\mathrm{FC}$ (dashed orange line) magnetization for $\mathrm{Cu}_{3}\left(\mathrm{C}_{6} \mathrm{O}_{6}\right)_{2}$ in an applied $\mathrm{DC}$ magnetic field of $100 \mathrm{Oe}$. The inset is molar paramagnetic susceptibility of $\mathrm{Cu}_{3}\left(\mathrm{C}_{6} \mathrm{O}_{6}\right)_{2}$ was fit against the temperature to Curie-Weiss law. (b) Magnetic hysteresis of $\mathrm{Cu}_{3}\left(\mathrm{C}_{6} \mathrm{O}_{6}\right)_{2}$ MOF at $2 \mathrm{~K}$ and $5 \mathrm{~K}$. (c) Temperature dependence of the product of the paramagnetic susceptibility and temperature $(X \mathrm{~m}, \mathrm{p} T)$. (d) Schematic representation of the antiferromagnetic coupling interactions in $\mathrm{Cu}_{3}\left(\mathrm{C}_{6} \mathrm{O}_{6}\right)_{2} \mathrm{MOF}$. The circles and triangles represent $\mathrm{Cu}$ ions and ligands in the MOF.

The antiferromagnetic exchange interactions were also reflected in the temperature dependence of the product of the paramagnetic susceptibility and temperature $\left(X_{\mathrm{m}, \mathrm{p}} T\right)$, which revealed a decreasing trend with the decrease of the temperature (Figure 6c). Based on the computational insight that the calculated spin resides on $d_{x-y 2}$ orbital of $\mathrm{Cu}$ ions, which favors intralayer interaction over intralayer interaction, we hypothesized that intralayer $\mathrm{Cu}$ coupling would dominate over interlayer coupling (see section 16 in Supporting Information for detailed discussion). The lack of magnetic ordering for $\mathrm{Cu}_{3}\left(\mathrm{C}_{6} \mathrm{O}_{6}\right)_{2}$ down to $1.8 \mathrm{~K}$ was also consistent with the observed antiferromagnetic interactions of $\mathrm{Cu}(\mathrm{II})$ spins within a Kagomé layer, similar to those found in the related $\mathrm{Cu}-\mathrm{BHT}\left(\mathrm{BHT}=\right.$ benzenehexathiol ${ }^{[43]}$ and $\mathrm{Cu}_{3}(\mathrm{HHTP})_{2}(\mathrm{HHTP}=\text { hexahydroxytriphenylene })^{[46]}$ system.

To assess the antiferromagnetic coupling interactions between the adjacent $\mathrm{Cu}$ (II) cations within a layer (Figure 6d), we analyzed the temperature-dependent $X_{\mathrm{m}, \mathrm{p}}$ data by hightemperature series expansion (see Supporting Information for details) ${ }^{[47]}$ The obtained exchange coupling constant for adjacent $\mathrm{Cu}$ (II) cations was $\mathrm{J} / \mathrm{K}_{\mathrm{B}}=-20 \mathrm{~K}\left(-13.9 \mathrm{~cm}^{-1}\right)$. This coupling constant was much larger than that in $\mathrm{Cu}_{3}(\mathrm{HHTP})$ complex $(-2.76$ $\left.\mathrm{cm}^{-1}\right)^{[27 \mathrm{c}]}$ and $\mathrm{Cu}_{3}(\mathrm{HHTP})_{2} \mathrm{MOF}\left(\mathrm{J} / \mathrm{k}_{\mathrm{B}}=-2 \mathrm{~K}\right),{ }^{[46]}$ demonstrating a stronger antiferromagnetic coupling interaction of adjacent $\mathrm{Cu}$ (II) ions in $\mathrm{Cu}_{3}\left(\mathrm{C}_{6} \mathrm{O}_{6}\right)_{2} \mathrm{MOF}$ system, which was possibly ascribed to the shorter $\mathrm{Cu}(\mathrm{II})-\mathrm{Cu}(\mathrm{II})$ distance in $\mathrm{Cu}_{3}\left(\mathrm{C}_{6} \mathrm{O}_{6}\right)_{2}(6.5 \AA$ vs $11.1 \AA$ in ref. [27c] and [45]). Below $4.8 \mathrm{~K}, X_{\mathrm{m}, \mathrm{p}} T$ value was even smaller than 0.375 emu K mol${ }^{-1}$ (calculated $\mu_{\text {eff }}<1.73 \mu_{\mathrm{B}}$ for each $\mathrm{Cu}_{3}\left(\mathrm{C}_{6} \mathrm{O}_{6}\right)_{2} \cdot 6 \mathrm{H}_{2} \mathrm{O}$ unit), indicating the existence of the across- $\mathrm{Cu}$ antiferromagnetic coupling interactions (indicated as $J_{1}$ ' and $J_{2}$ in Figure $6 \mathrm{~d}$ ). The across- $\mathrm{Cu}$ antiferromagnetic couplings can be favorable in $\mathrm{Cu}_{3}\left(\mathrm{C}_{6} \mathrm{O}_{6}\right)_{2}$ MOF system considering that the across$\mathrm{Cu} \mathrm{Cu(II)-Cu(II)} \mathrm{distances} \mathrm{in} \mathrm{this} \mathrm{MOF} \mathrm{(11.3} \mathrm{and} 13.0 \AA$ ) were comparable with those in the triphenylene-bridged $\mathrm{Cu}$ complexes $\left(11.1 \AA\right.$ ̊). ${ }^{[27 c, 46]}$

\section{Conclusion}

This paper demonstrates the unambiguous structural elucidation of $\mathrm{Cu}_{3}\left(\mathrm{C}_{6} \mathrm{O}_{6}\right)_{2}$ MOF by MicroED with sub-angstrom precision. This achievement provides a new level of insight into the hydration, coordination variation and distortion, and stacking features of this material. Cofacial stacking of adjacent bilayers over a remarkably short interplanar distance of $2.70 \AA$ has led us to propose pancake bonding interactions, which were not previously reported in 2D layered materials. Experimental studies and electronic band structure analysis indicated the semiconductive feature of the MOF, which was likely related to the localized feature of pancake bonds. The magnetism of $\mathrm{Cu}_{3}\left(\mathrm{C}_{6} \mathrm{O}_{6}\right)_{2}$-dominated by the paramagnetic $\mathrm{Cu}(\mathrm{II})$ ionsshowed strong geometric magnetic frustration resulting from the Kagomé arrangement of $\mathrm{Cu}$ (II) in the MOF. This property may be of further interest for evaluating this material as a potential candidate for quantum spin liquid. ${ }^{[44,48]}$ We anticipate that the fundamental study presented herein will open the avenue for indepth investigation of other conductive frameworks and 2D layered materials through the exploitation and manipulation of different types of stacking forces. Future studies using devices fabricated from large single crystals and precisely controlled number of layers of the 2D layered MOFs should clarify the anisotropic and intrinsic electronic properties and minimize the nontrivial effects of structural defects, impurities, and grain boundaries in this general class of materials. ${ }^{[1 \mathrm{~b}, 11 \mathrm{~b}, 11 \mathrm{~d}]}$

\section{Acknowledgements}


K.A.M. acknowledges support from startup funds provided by Dartmouth College, Army Research Office Young Investigator Program Grant No. W911NF-17-1-0398, and Camille Dreyfus Teacher-Scholar Award. K.A.M. and Z.M. also thank the National Science Foundation EPSCoR award (\#1757371), US Army Cold Regions Research and Engineering Lab (Award No. W913E519C0008), and Arthur L. Irving Institute for Energy and Society at Dartmouth. H.M.N. would like to acknowledge the Packard Foundation for generous support. C.G.J. would like to acknowledge the National Science Foundation Graduate Research Fellowship Program (DGE-1650604) for funding. S.F. thanks the International Research Support Initiative Program, Higher Education Commission Pakistan. The authors acknowledge beamline 11-BM of the Advanced Photon Source for the synchrotron $\mathrm{PXRD}$ measurement. This work made use of the Cornell Center for Materials Research Facilities supported by the National Science Foundation under Award Number DMR1719875.

Keywords: conductive metal-organic framework $\cdot$ microcrystal electron diffraction $•$ pancake bond $\bullet$ two-dimensional material $•$ quantum spin liquid

[1] a) L. Sun, M. G. Campbell, M. Dincă, Angew. Chem. Int. Ed. 2016 55, 3566-3579; Angew. Chem. 2016, 128, 3628-3642; b) L. S. Xie, G. Skorupskii, M. Dincă, Chem. Rev. 2020, 120, 8536-8580.

[2] C. Tan, X. Cao, X. J. Wu, Q. He, J. Yang, X. Zhang, J. Chen, W. Zhao, S. Han, G. H. Nam, M. Sindoro, H. Zhang, Chem. Rev. 2017 117, 6225-6331.

[3] a) M. Dincă, F. Léonard, MRS Bulletin 2016, 41, 854-857; b) G. Wu, J. Huang, Y. Zang, J. He, G. Xu, J. Am. Chem. Soc. 2017, 139 1360-1363.

[4] a) J. A. DeGayner, I. R. Jeon, L. Sun, M. Dincă, T. D. Harris, J. Am. Chem. Soc. 2017, 139, 4175-4184; b) R. Dong, Z. Zhang, D. C Tranca, S. Zhou, M. Wang, P. Adler, Z. Liao, F. Liu, Y. Sun, W. Shi, Z. Zhang, E. Zschech, S. C. B. Mannsfeld, C. Felser, X. Feng, Nat Commun. 2018, 9, 2637; c) C. Yang, R. Dong, M. Wang, P. S Petkov, Z. Zhang, M. Wang, P. Han, M. Ballabio, S. A. Brauninger Z. Liao, J. Zhang, F. Schwotzer, E. Zschech, H. H. Klauss, E. Canovas, S. Kaskel, M. Bonn, S. Zhou, T. Heine, X. Feng, Nat Commun. 2019, 10, 3260.

[5] a) M. G. Campbell, S. F. Liu, T. M. Swager, M. Dincă, J. Am. Chem. a) M. G. Campbell, S. F. Liu, T. M. Swager, M. Dincă, J. Am. Chem
Soc. 2015, 137, 13780-13783; b) M. K. Smith, K. A. Mirica, J. Am Chem. Soc. 2017, 139, 16759-16767; c) M.-S. Yao, X.-J. Lv, Z.-H Fu, W.-H. Li, W.-H. Deng, G.-D. Wu, G. Xu, Angew. Chem. Int. Ed 2017, 129, 16737-16741; Angew. Chem. 2017, 129, 16737-16741; d) Z. Meng, A. Aykanat, K. A. Mirica, J. Am. Chem. Soc. 2019, 141 2046-2053.

[6] a) C. A. Downes, S. C. Marinescu, J. Am. Chem. Soc. 2015, 137 13740-13743; b) R. Dong, M. Pfeffermann, H. Liang, Z. Zheng, X Zhu, J. Zhang, X. Feng, Angew. Chem. Int. Ed. 2015, 54, 1205812063; Angew. Chem. 2015, 127, 12226-12231; c) E. M. Miner, T. Fukushima, D. Sheberla, L. Sun, Y. Surendranath, M. Dincă, Nat Commun. 2016, 7, 10942; d) H. X. Zhong, K. H. Ly, M. C. Wang, Y. Krupskaya, X. C. Han, J. C. Zhang, J. Zhang, V. Kataev, B. Buchner, I. M. Weidinger, S. Kaskel, P. Liu, M. W. Chen, R. H. Dong, X. L. Feng, Angew. Chem. Int. Ed. 2019, 58, 10677-10682; Angew. Chem. 2019, 131, 10787-10792.

[7] a) D. Sheberla, J. C. Bachman, J. S. Elias, C. J. Sun, Y. Shao-Horn, M. Dincă, Nat. Mater. 2016, 16, 220-225; b) D. Feng, T. Lei, M. R. Lukatskaya, J. Park, Z. Huang, M. Lee, L. Shaw, S. Chen, A. A Yakovenko, A. Kulkarni, J. Xiao, K. Fredrickson, J. B. Tok, X. Zou, Y. Cui, Z. Bao, Nat. Energy 2018, 3, 30-36; c) K. W. Nam, S. S. Park R. Dos Reis, V. P. Dravid, H. Kim, C. A. Mirkin, J. F. Stoddart, Nat Commun. 2019, 10, 4948.

[8] a) G. Minguez Espallargas, E. Coronado, Chem. Soc. Rev. 2018, 47, 533-557; b) A. E. Thorarinsdottir, T. D. Harris, Chem. Rev. 2020 120, 8716-8789.

[9] a) A. J. Clough, J. M. Skelton, C. A. Downes, A. A. de la Rosa, J. W. Yoo, A. Walsh, B. C. Melot, S. C. Marinescu, J. Am. Chem. Soc 2017, 139, 10863-10867; b) S. S. Park, E. R. Hontz, L. Sun, C. H. Hendon, A. Walsh, T. Van Voorhis, M. Dincă, J. Am. Chem. Soc. 2015, 137, 1774-1777; c) G. Skorupskii, B. A. Trump, T. W. Kasel,
C. M. Brown, C. H. Hendon, M. Dincă, Nat. Chem. 2020, 12, 131136.

[10] a) Z. Fei, W. Zhao, T. A. Palomaki, B. Sun, M. K. Miller, Z. Zhao, J. Yan, X. Xu, D. H. Cobden, Nature 2018, 560, 336-339; b) Y. Cao, V. Fatemi, S. Fang, K. Watanabe, T. Taniguchi, E. Kaxiras, P. JarilloHerrero, Nature 2018, 556, 43-50.

[11] a) M. Hmadeh, Z. Lu, Z. Liu, F. Gándara, H. Furukawa, S. Wan, V. Augustyn, R. Chang, L. Liao, F. Zhou, E. Perre, V. Ozolins, K. Suenaga, X. Duan, B. Dunn, Y. Yamamto, O. Terasaki, O. M. Yaghi, Chem. Mater. 2012, 24, 3511-3513; b) R. W. Day, D. K. Bediako, M. Rezaee, L. R. Parent, G. Skorupskii, M. Q. Arguilla, C. H. Hendon, I. Stassen, N. C. Gianneschi, P. Kim, M. Dincă, ACS Cent. Sci. 2019, 5, 1959-1964; c) J. H. Dou, M. Q. Arguilla, Y. Luo, J. Li, W. Zhang, L. Sun, J. L. Mancuso, L. Yang, T. Chen, L. R. Parent, G. Skorupskii, N. J. Libretto, C. Sun, M. C. Yang, P. V. Dip, E. J. Brignole, J. T. Miller, J. Kong, C. H. Hendon, J. Sun, M. Dincă, Nat. Mater. 2021 20, 222-228; d) D. G. Ha, M. Rezaee, Y. Han, S. A. Siddiqui, R. W Day, L. S. Xie, B. J. Modtland, D. A. Muller, J. Kong, P. Kim, M. Dincă, M. A. Baldo, ACS Cent. Sci. 2021, 7, 104-109.

[12] a) D. Sheberla, L. Sun, M. A. Blood-Forsythe, S. Er, C. R. Wade, C. K. Brozek, A. Aspuru-Guzik, M. Dincă, J. Am. Chem. Soc. 2014, 136, 8859-8862; b) X. Huang, P. Sheng, Z. Tu, F. Zhang, J. Wang, H. Geng, Y. Zou, C. A. Di, Y. Yi, Y. Sun, W. Xu, D. Zhu, Nat. Commun 2015, 6, 7408.

[13] a) D. Shi, B. L. Nannenga, M. G. Iadanza, T. Gonen, Elife 2013, 2 e01345; b) B. L. Nannenga, D. Shi, A. G. W. Leslie, T. Gonen, Nat. Methods 2014, 11, 927-930.

[14] B. L. Nannenga, T. Gonen, Nat. Methods 2019, 16, 369-379.

[15] C. G. Jones, M. W. Martynowycz, J. Hattne, T. J. Fulton, B. M. Stoltz, J. A. Rodriguez, H. M. Nelson, T. Gonen, ACS Cent. Sci. 2018, 4 1587-1592.

[16] C. G. Jones, M. Asay, L. J. Kim, J. F. Kleinsasser, A. Saha, T. J. Fulton, K. R. Berkley, D. Cascio, A. G. Malyutin, M. P. Conley, B. M. Stoltz, V. Lavallo, J. A. Rodriguez, H. M. Nelson, ACS Cent. Sci. 2019, 5, 1507-1513.

[17] M. Gemmi, E. Mugnaioli, T. E. Gorelik, U. Kolb, L. Palatinus, P Boullay, S. Hovmoller, J. P. Abrahams, ACS Cent. Sci. 2019, 5 1315-1329.

[18] a) J. Jiang, J. L. Jorda, J. Yu, L. A. Baumes, E. Mugnaioli, M. J. Diaz-Cabanas, U. Kolb, A. Corma, Science 2011, 333, 1131-1134 b) J. Simancas, R. Simancas, P. J. Bereciartua, J. L. Jorda, F. Rey, A. Corma, S. Nicolopoulos, P. Pratim Das, M. Gemmi, E. Mugnaioli, J. Am. Chem. Soc. 2016, 138, 10116-10119.

[19] a) D. Denysenko, M. Grzywa, M. Tonigold, B. Streppel, I. Krkljus, M. Hirscher, E. Mugnaioli, U. Kolb, J. Hanss, D. Volkmer, Chem. Eur. J. 2011, 17, 1837-1848; b) S. Yuan, J. S. Qin, H. Q. Xu, J. Su, D. Rossi, Y. Chen, L. Zhang, C. Lollar, Q. Wang, H. L. Jiang, D. H. Son, H. Xu, Z. Huang, X. Zou, H. C. Zhou, ACS Cent. Sci. 2018, 4, 105 111 ; c) D. Lenzen, J. Zhao, S. J. Ernst, M. Wahiduzzaman, A. Ken Inge, D. Frohlich, H. Xu, H. J. Bart, C. Janiak, S. Henninger, G. Maurin, X. Zou, N. Stock, Nat. Commun. 2019, 10, 3025; d) Z Huang, M. Ge, F. Carraro, C. J. Doonan, P. Falcaro, X. Zou, Faraday Discuss. 2020, 225, 118-132.

[20] a) Y. B. Zhang, J. Su, H. Furukawa, Y. Yun, F. Gandara, A. Duong X. Zou, O. M. Yaghi, J. Am. Chem. Soc. 2013, 135, 16336-16339 b) T. Sun, C. E. Hughes, L. Guo, L. Wei, K. D. M. Harris, Y. B. Zhang, Y. Ma, Angew. Chem. Int. Ed. 2020, 59, 22638-22644; Angew. Chem. 2020, 132, 22827-22833.

[21] a) J. Park, A. C. Hinckley, Z. Huang, D. Feng, A. A. Yakovenko, M Lee, S. Chen, X. Zou, Z. Bao, J. Am. Chem. Soc. 2018, 140,14533 14537; b) Q. Jiang, P. Xiong, J. Liu, Z. Xie, Q. Wang, X. Q. Yang, E. $\mathrm{Hu}, \mathrm{Y}$. Cao, J. Sun, Y. Xu, L. Chen, Angew. Chem. Int. Ed. 2020, 59 5273-5277; Angew. Chem. 2020, 132, 5311-5315; c) J. Nyakuchena, S. Ostresh, D. Streater, B. Pattengale, J. Neu, C. Fiankor, W. Hu, E. D. Kinigstein, J. Zhang, X. Zhang, C. A Schmuttenmaer, J. Huang, J. Am. Chem. Soc. 2020, 142, 21050 21058.

[22] Cambridge Crystallographic Data Centre deposition number 2069514 contains the supplementary crystallographic data for this structure.

[23] T. Ma, E. A. Kapustin, S. X. Yin, L. Liang, Z. Zhou, J. Niu, L.-H. Li, Y. Wang, J. Su, J. Li, X. Wang, W. D. Wang, W. Wang, J. Sun, O. M. Yaghi, Science 2018, 361, 48-52.

[24] J. H. Dou, L. Sun, Y. Ge, W. Li, C. H. Hendon, J. Li, S. Gul, J. Yano, E. A. Stach, M. Dincă, J. Am. Chem. Soc. 2017, 139, 13608-13611. R. Dong, P. Han, H. Arora, M. Ballabio, M. Karakus, Z. Zhang, C. Shekhar, P. Adler, P. S. Petkov, A. Erbe, S. C. B. Mannsfeld, C. Felser, T. Heine, M. Bonn, X. Feng, E. Canovas, Nat. Mater. 2018 17, 1027-1032.

[26] M. C. Biesinger, L. W. M. Lau, A. R. Gerson, R. S. C. Smart, Appl. Surf. Sci. 2010, 257, 887-898.

[27] a) C. G. Pierpont, C. W. Lange, in Prog. Inorg. Chem., 2007, pp. 331-442; b) V. I. Ovcharenko, E V Gorelik, S. V. Fokin, G V. Romanenko, V. N. Ikorskii, A. V. Krashilina, V. K. Cherkasov, G. A Abakumov, J. Am. Chem. Soc. 2007, 129, 10512-10521; c) L. Yang X. He, M. Dincă, J. Am. Chem. Soc. 2019, 141, 10475-10480. 
[28] A. Banerjee, A. Saha, B. K. Saha, Cryst. Growth Des. 2019, 19, 2245-2252.

[29] A. T. M. Fiori, D. H. Nakahata, A. Cuin, W. R. Lustri, P. P. Corbi, Polyhedron 2017, 121, 172-179.

[30] a) C. A. Hunter, J. K. M. Sanders, J. Am. Chem. Soc. 1990, 112 5525-5534; b) K. P. Goetz, D. Vermeulen, M. E. Payne, C. Kloc, L. E. McNeil, O. D. Jurchescu, J. Mater. Chem. C 2014, 2, 3065-3076.

[31] a) Z.-h. Cui, H. Lischka, H. Z. Beneberu, M. Kertesz, J. Am. Chem. Soc. 2014, 136, 12958-12965; b) K. Molčanov, V. Milašinović, B Kojić-Prodić, Cryst. Growth Des. 2019, 19, 5967-5980.

[32] a) M. E. Itkis, Science 2002, 296, 1443-1445; b) S. Suzuki, Y. Morita K. Fukui, K. Sato, D. Shiomi, T. Takui, K. Nakasuji, J. Am. Chem. Soc. 2006, 128, 2530-2531.

[33] a) J. C. Barnes, A. C. Fahrenbach, D. Cao, S. M. Dyar, M. Frasconi, M. A. Giesener, D. Benitez, E. Tkatchouk, O. Chernyashevskyy, W. H. Shin, H. Li, S. Sampath, C. L. Stern, A. A. Sarjeant, K. J. Hartlieb, Z. C. Liu, R. Carmieli, Y. Y. Botros, J. W. Choi, A. M. Z. Slawin, J. B. Ketterson, M. R. Wasielewski, W. A. Goddard, J. F. Stoddart, Science 2013, 339, 429-433; b) C. Gourlaouen, S. Vela, S. Choua, M. Berville, J. A. Wytko, J. Weiss, V. Robert, Phys. Chem. Chem. Phys. 2018, 20, 27878-27884.

[34] X. Zheng, Y. Zhang, N. Cao, X. Li, S. Zhang, R. Du, H. Wang, Z. Ye, Y. Wang, F. Cao, H. Li, X. Hong, A. C. H. Sue, C. Yang, W.-G. Liu, H. Li, Nat. Commun. 2018, 9, 1961.

[35] K. Cai, H. Mao, W.-G. Liu, Y. Qiu, Y. Shi, L. Zhang, D. Shen, H. Chen, Y. Jiao, H. Wu, Z. Liu, Y. Feng, C. L. Stern, M. R. Wasielewski, W. A. Goddard, J. F. Stoddart, J. Am. Chem. Soc. 2020, 142, 71907197.

[36] J. B. Torrance, B. A. Scott, B. Welber, F. B. Kaufman, P. E. Seiden, Phys Rev B 1979, 19, 730-741.

[37] a) M. Kertesz, Chem. Eur. J. 2019, 25, 400-416; b) K. Cai, L. Zhang, R. D. Astumian, J. F. Stoddart, Nat. Rev. Chem. 2021, 5, 447-465. R. S. Mulliken, W. B. Person, Molecular Complexes, Chapter 16.

Wiley \& Sons: New York, 1969. R. M. Stolz, A. Mahdavi-Shakib, B. G. Frederick, K. A. Mirica, Chem.

[40] Mater. 2020, 32, 7639-7652.

[41] J. L. Mancuso, A. M. Mroz, K. N. Le, C. H. Hendon, Chem. Rev. 2020, 120, 8641-8715.

[42] L. E. Darago, M. L. Aubrey, C. J. Yu, M. I. Gonzalez, J. R. Long, J. Am. Chem. Soc. 2015, 137, 15703-15711.

[43] X. Huang, S. Zhang, L. Liu, L. Yu, G. Chen, W. Xu, D. Zhu, Angew. Chem. Int. Ed. 2018, 57, 146-150; Angew. Chem. 2018, 130, 152156.

[44] a) P.W. Anderson, Science 1987, 235, 1196-1198; b) S. Yan, D. A. Huse, S. R. White, Science 2011, 332, 1173-1176; c) C. Broholm, R. J. Cava, S. A. Kivelson, D. G. Nocera, M. R. Norman, T. Senthil, Science 2020, 367; d) J. R. Chamorro, T. M. McQueen, T. T. Tran, Chem. Rev. 2021, 121, 2898-2934.

[45] A. P. Ramirez, Annu. Rev. Mater. Sci. 1994, 24, 453-480.

[46] Y. Misumi, A. Yamaguchi, Z. Zhang, T. Matsushita, N. Wada, M. Tsuchiizu, K. Awaga, J. Am. Chem. Soc. 2020, 142, 16513-16517.

[47] A. Lohmann, H. J. Schmidt, J. Richter, Phys Rev B 2014, 89.
[48] Rondinelli, D. E. Freedman, Chem. Sci. 2020, 11, 5922-5928. 


\section{WILEY-VCH}

\section{RESEARCH ARTICLE}

\section{Entry for the Table of Contents}

An unambiguous structural elucidation using microcrystal electron diffraction provides insight into unique properties of a layered conductive metal-organic framework (MOF) $\mathrm{Cu}_{3}\left(\mathrm{C}_{6} \mathrm{O}_{6}\right)_{2}$. The presence of strong interlayer electronic coupling exerts a profound effect on the electrical and magnetic properties of the MOF.

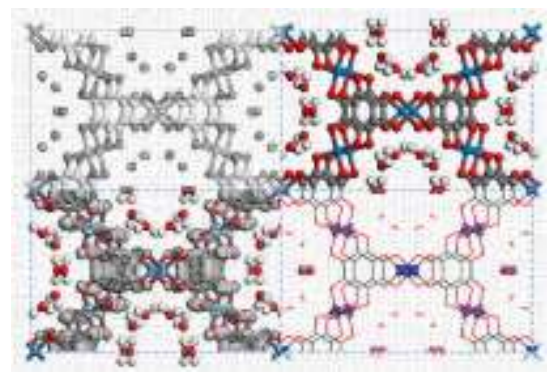

Institute and/or researcher Twitter usernames: @KMirica @TheNelsonLab

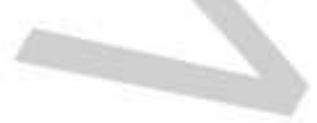

